\title{
Determination of Spinopelvic Parameters in Degenerative Lumbar Spondylolisthesis Patients Undergoing Lumbosacral Spine Fusion Surgery: The Lesson Learnt
}

\author{
Sorayouth CHUMNANVEJ, Noppatee SEGKHAPHANT \\ Mahidol University, Faculty of Medicine Ramathibodi Hospital, Surgery Department, Neurosurgery Division, Bangkok, Thailand \\ Corresponding author: Sorayouth CHUMNANVEJ sorayouth.chu@mahidol.edu
}

\section{ABSTRACT}

AIM: To investigate the relationship between the deformity correction and subsequent alterations in spinopelvic parameters after surgical correction in degenerative lumbar spondylolisthesis patients.

MATERIAL and METHODS: About 100 adult patients were recruited in the study. The eligible cases received surgical treatment from 2003 to 2013 at Ramathibodi Hospital.

RESULTS: No significant change was observed in any of the spinopelvic parameters after correction of slip degree following surgery in the transforaminal lumbar interbody fusion group.

CONCLUSION: Lumbar spinal fusion procedures cause significant changes in spinopelvic parameters and are efficient in correcting the height of disc in the transforaminal lumbar interbody fusion group.

KEYWORDS: Degenerative lumbar spondylolisthesis, Spinopelvic parameters, Spinal stenosis, Spinal disorder

\section{INTRODUCTION}

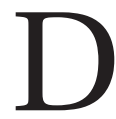
egenerative lumbar spondylolisthesis (DLS) is a frequently-observed spinal disorder in motion segments, particularly at the L4-5 level $(6,18)$. The unique features of DLS are long-standing degeneration with dysfunction of the intervertebral discs and loss of facet joints posteriorly $(15,31)$. It seldom occurs before the age of 50 years and is approximately four times more prevalent in women than in men (15). Its features include spinal stenosis with an anterior translation not exceeding $30 \%$ of the width of the vertebral body (18). DLS patients may suffer from back and leg pain. DLS can differ in disc and facet degeneration, magnitude of slip, and motion at the segment on the basis of X-ray imaging $(14,16,18)$. The existing literature suggests that a variety of surgical techniques could provide satisfactory clinical results; however, the optimal management of DLS needs to be elucidated $(1,7,33)$. Thus, the objective parameters such as spinopelvic parameters are required $(9,11,29)$. Since spinopelvic parameters are intricately associated with the deformity, changes in spinopelvic parameters can be objectively determined after correction of the deformity $(10,17,23,25,28,38)$. Several studies have proposed methods for determination of spinopelvic parameters after surgical correction for DLS (2-5, $9,10,12,17,19,28,29,35,38)$.

The objectives of the present study were first, to assess the relationship between the amount of deformity correction and subsequent alterations in spinopelvic parameters following surgical treatment in DLS patients; second, to determine deformity parameters, which mainly destabilizes the postoperative restoration of spinopelvic sagittal alignment, and compare the amount of deformity correction between posterolateral fusion (PLF) and transforaminal lumbar interbody fusion (TLIF). 


\section{MATERIAL and METHODS}

\section{Subjects}

Following the IRB approval, sample size was calculated using the following formula: $N=\left(Z^{2} \sigma^{2}\right) / d^{2}$, where $N=$ number of sample size, $Z=1.96, \sigma=$ standard deviation and $\mathrm{d}=$ acceptable error $=1$. One hundred adult patients were recruited. The eligible cases were those (6) patients who had DLS and received surgical treatment in the period of 2003-2013 at the Neurosurgical Division, Surgery Department, Faculty of Medicine of Ramathibodi Hospital. Surgery was carried out on those patients who were suffering from back pain, radicular pain, or neurological claudication even after 3 months of conservative management (18). A total of 25 men and 75 women having an average age of 61 years were recruited. The study also included 7 patients with L3/4 degenerative spondylolisthesis and 93 patients with $\mathrm{L} 4 / 5$ degenerative spondylolisthesis. A total of 66 patients underwent PLF, and 34 patients received TLIF. The patients were followed-up for 26.9 months.

\section{Radiographic Measurements}

The lateral standing and anteroposterior (AP) radiographs of the lumbosacral spine including the head of femurs were obtained preoperatively and postoperatively. Measurement from the picture archiving and communication system (PACS) in Ramathibodi Hospital was performed with the agreement of both of the authors. Spinopelvic parameters such as lumbar slope $\left(\mathrm{L}_{4-5} \mathrm{~S}\right)$, lumbar tilt $\left(\mathrm{L}_{4-5} \mathrm{~T}\right)$, lumbar incidence $\left(\mathrm{L}_{4}\right.$ ${ }_{5}$ ), and lumbar lordosis (LL) were measured before and 3-6 months after surgery (average 4.3 months) as shown in the Figure $1 . L_{4-5} S$ refers to the angle between the horizontal line and the superior lumbar plate. $L_{4-5} T$ refers to the angle between a vertical line and the line connecting the hip axis and the middle of the lumbar endplate. $\mathrm{L}_{4-5} \mathrm{I}$ is defined as the angle between the line drawn from the center of the femoral heads to the middle point of the lumbar endplate and the line perpendicular to the lumbar endpoint. The Cobb angle between the upper L1 endplate and the lower L5 endplate was used to measure LL. The slip degree (SD) and height of disc (HOD) were measured to evaluate the deformity parameters. Following surgery, changes in the deformity parameters were measured to determine the correction of the deformity. SD is the distance between two extended lines of the posterior aspect of the upper and lower lumbar vertebral body. The HOD refers to the mean height of the primary intervertebral disc and the most posterior disc.

\section{Statistics}

Stata data analysis software (version 12, StataCorp LP) was used for statistical analysis. Pearson correlation and a paired student $\mathrm{t}$ test were determined to analyze data. Statistical significance was considered for a $p$-value $<0.05$.

\section{RESULTS}

A significant change was observed in SD after surgery in all cases (Table I, II). Overall, there was $2.96 \mathrm{~mm}$ decrease in SD by the postoperative procedure. In the PLF group, SD decreased by $2.35 \mathrm{~mm}(95 \% \mathrm{Cl}:-2.4,12.27)$. In the TLIF group, SD decreased by $2.505 \mathrm{~mm}(95 \% \mathrm{Cl}:-3.01,11.77)$. As shown in Table III, the groups did not show any significant difference $(p=0.868)$ in terms of SD value. In the PLF group, HOD decreased by $0.14 \mathrm{~mm}(95 \% \mathrm{Cl}:-4.6,5.2)$. In the TLIF
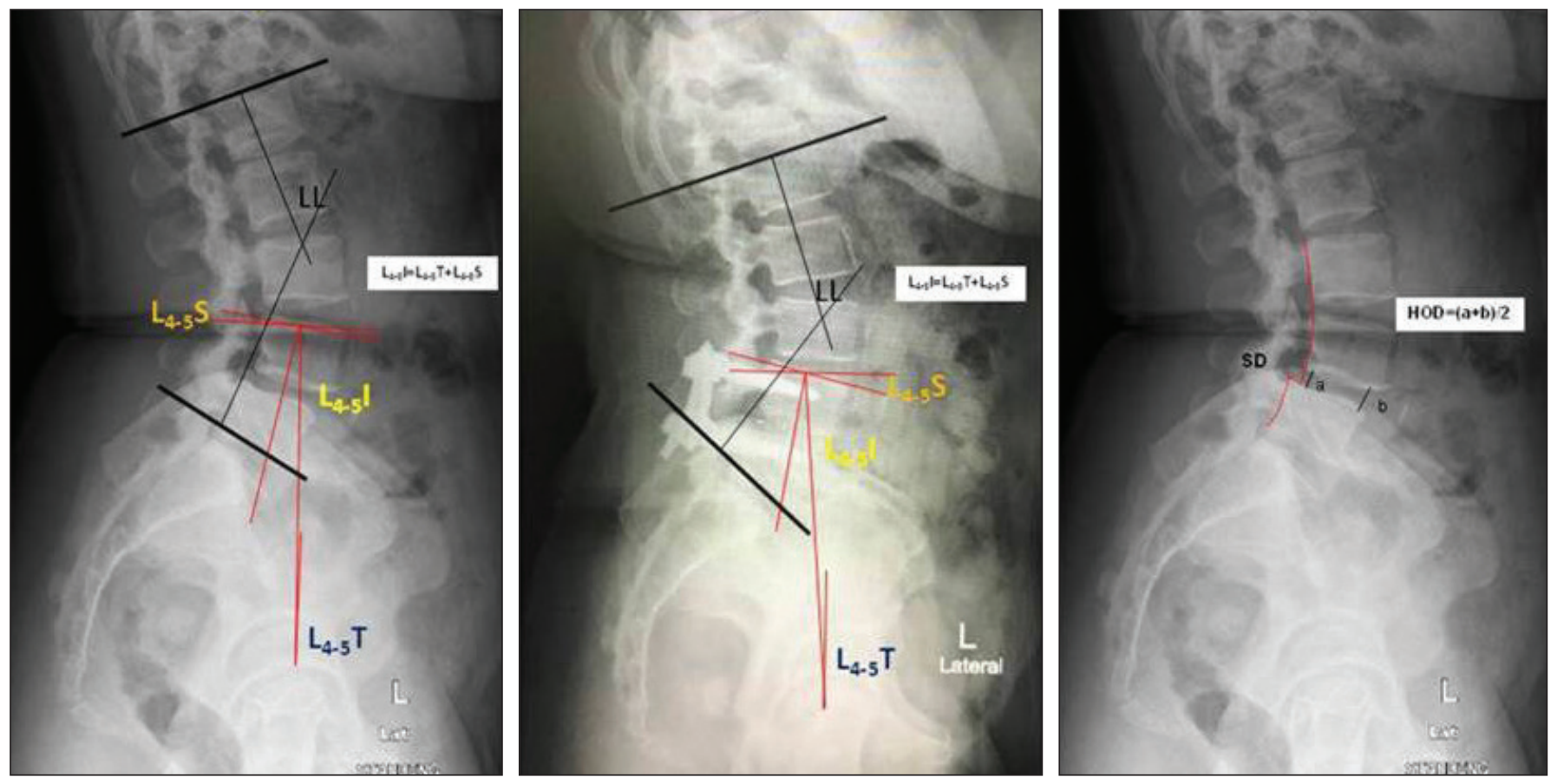

Figure 1: Radiographic images demonstrating measurement of spinopelvic parameters. $\mathbf{L}_{4-5} \mathbf{I}=$ lumbar incidence, $\mathbf{L}_{4-5} \mathbf{T}=$ lumbar tilt, $\mathbf{L}_{4-5} \mathbf{S}$ = lumbar slope, $\mathbf{L L}=$ lumbar lordosis, HOD = height of disc, and SD = slip degree. 
group, HOD increased by $0.9175 \mathrm{~mm}$ (95\% Cl:-3.03,5.89). This difference observed between the PLF and TLIF groups was statistically significant $(p=0.022)$ in Table IV.

The spinopelvic parameters were restored significantly $3-6$ months after surgery in all cases (Table V). $\mathrm{L}_{4-5} \mathrm{I}$ is a constant as there was no significant change, while $L_{4-5} S$ increased by 2.53 degrees, $L_{4-5} T$ decreased by 3.45 degrees, and $L L$ increased by 3.18 degrees. The analysis of L4/5 DLS patients (excluding L3/4 DLS due to a small number of patients) in the PLF and TLIF groups is represented in Table 5 . In the PLF group, $\mathrm{L}_{4-5} \mathrm{~T}$

Table I: Slip Degree (SD) and Height of Disc (HOD) Parameters Before and After Surgery in all Patients

\begin{tabular}{lcc}
\hline & SD $(\mathrm{mm})$ & HOD $(\mathrm{mm})$ \\
\hline Preoperative & $9.9 \pm 3.3$ & $6.03 \pm 2.1$ \\
\hline Postoperative & $7.01 \pm 2.9$ & $6.28 \pm 2.1$ \\
\hline $\mathrm{p}$ & $<0.001$ & 0.187 \\
\hline
\end{tabular}

was significantly changed following surgery. In the TLIF group, $\mathrm{L}_{4-5} \mathrm{~S}, \mathrm{~L}_{4-5} \mathrm{~T}$, and $\mathrm{LL}$ were significantly changed after surgery. However, there was no significant difference in spinopelvic parameters between the PLF and TLIF groups (Table VI).

Except for $\mathrm{L}_{4-5} \mathrm{~T}$ and $\mathrm{LL}$ in the TLIF group, SD correction after surgery did not cause any significant changes in the spinopelvic parameters in both the PLF and TLIF groups (Tables VII and VIII). In all cases, restoration of the HOD demonstrated a significant correlation with the changes in $\mathrm{L}_{4-5} \mathrm{~S}(r=0.213$, $p=0.034)$ and $\mathrm{LL}(\mathrm{r}=0.239, \mathrm{p}=0.017)$ (Table VII). In the TLIF group, restoration of the HOD was found to be correlated with the change in $\mathrm{L}_{4-5} \mathrm{~T}(\mathrm{r}=-0.362, \mathrm{p}=0.004)$, whereas in the PLF group, no significant changes were observed in any pelvic parameter (Table VIII).

\section{DISCUSSION}

$\mathrm{LL}$ is one of the global spinal alignment components whose normative value is between $40^{\circ}$ and $60^{\circ}$ in the adult population $(5,25,28,41)$. It is crucial to maintain proper upright posture

Table II: Comparison of Deformity Parameters of L4/5 DLS Before and After Surgery in the PLF and TLIF Groups

\begin{tabular}{lcccc}
\hline & \multicolumn{2}{c}{ SD $(\mathbf{m m})$} & \multicolumn{2}{c}{ HOD $(\mathbf{m m})$} \\
\cline { 2 - 5 } & PLF & TLIF & PLF & TLIF \\
\hline Preoperative & $10.56 \pm 3.3$ & $9.34 \pm 3.3$ & $5.88 \pm 2.0$ & $6.28 \pm 2.1$ \\
\hline Postoperative & $7.68 \pm 2.9$ & $6.20 \pm 2.8$ & $5.83 \pm 2.2$ & $7.21 \pm 1.4$ \\
\hline $\mathrm{p}$ & $<\mathbf{0 . 0 0 1}$ & $<\mathbf{0 . 0 0 1}$ & 0.826 & $\mathbf{0 . 0 0 9}$ \\
\hline
\end{tabular}

Table III: Amount of Deformity Correction Between PLF and TLIF

\begin{tabular}{llll}
\hline & \multicolumn{1}{c}{ PLF } & \multicolumn{1}{c}{ TLIF } & p \\
\hline$\Delta$ SD $(95 \% \mathrm{Cl})$ & $2.35(-2.4,12.27)$ & $2.505(-3.01,11.77)$ & 0.868 \\
\hline$\Delta \mathrm{HOD}(95 \% \mathrm{Cl})$ & $0.14(-4.6,5.2)$ & $0.9175(-3.03,5.89)$ & $\mathbf{0 . 0 2 2}$ \\
\hline
\end{tabular}

Table IV: Degree of Spinopelvic Parameters Before and After Surgery in All Patients

\begin{tabular}{lcccc}
\hline & $\mathbf{L}_{\mathbf{4 - 5}} \mathbf{I}$ (degrees) & $\mathbf{L}_{\mathbf{4 - 5}} \mathbf{S}$ (degrees) & $\mathbf{L}_{\mathbf{4 - 5}} \mathbf{T}$ (degrees) & $\mathbf{L L}$ (degrees) \\
\hline Preoperative & 51.85 & 29.16 & 24.05 & 32.19 \\
\hline Postoperative & 50.67 & 31.69 & 20.60 & 35.37 \\
\hline $\mathrm{p}$ & $\mathbf{0 . 0 4}$ & $<0.001$ & $<0.001$ & $\mathbf{0 . 0 0 2}$ \\
\hline
\end{tabular}

Table V: Spinopelvic Parameters of L4/5 DLS Before and After Surgery in the PLF and TLIF Groups

\begin{tabular}{lcccccccc}
\hline & \multicolumn{2}{c}{$\mathbf{L}_{4-5} \mathbf{l}$ (degrees) } & \multicolumn{2}{c}{$\mathbf{L}_{4-5} \mathbf{S}(\mathbf{m m})$} & \multicolumn{2}{c}{$\mathbf{L}_{4-5} \mathbf{T}$ (degrees) } & \multicolumn{2}{c}{ LL (degrees) } \\
\hline Operation & PLF & TLIF & PLF & TLIF & PLF & TLIF & PLF & TLIF \\
\hline Preoperative & 53.41 & 49.88 & 30.28 & 27.53 & 24.67 & 23.06 & 33.53 & 29.44 \\
\hline Postoperative & 51.71 & 49.16 & 31.98 & 31.16 & 21.46 & 19.38 & 35.75 & 34.31 \\
\hline $\mathrm{p}$ & 0.077 & 0.481 & 0.052 & $\mathbf{0 . 0 0 2}$ & $<0.001$ & $\mathbf{0 . 0 1 3}$ & 0.067 & $\mathbf{0 . 0 2 1}$ \\
\hline
\end{tabular}


(36). Decreasing lordosis causes failure in maintaining spinal balance resulting in back pain and disability $(4,10)$. The pelvis is the base of spine and it has been determined that the spine must be in coordination with the pelvis for the spine to be placed so as to attain the upright posture of the human body $(20,34)$. In addition, with respect to spinopelvic alignment, understanding the morphometric static and dynamic parameters is crucial for preoperative evaluation (12). The spinopelvic parameters include $\mathrm{L}_{4-5} \mathrm{I}, \mathrm{L}_{4-5} \mathrm{~T}$, and $\mathrm{L}_{4-5} \mathrm{~S}$. In addition, $\mathrm{L}_{4-5} \mathrm{I}$ is a fundamental constant parameter after adolescence $(2,22,24,39)$ and $L_{4-5} I=L_{4-5} S+L_{4-5} T(21,22,39)$. In the standing position, pelvic morphology is indicated by $L_{4-5} I$ (24). It is associated with the anatomic morphology of the pelvis and modulates the sagittal spinal alignment $(21,22,32,36,38)$. The normative values of $\mathrm{L}_{4-5} \mathrm{l}$ have a range of $50^{\circ}-55^{\circ}(2,5,24,39,40)$. The results of our study are in agreement with these values. Regarding the correlation of pelvic parameters, a high $\mathrm{L}_{4-5}$ I will cause a high $\mathrm{L}_{4-5} \mathrm{~S}$ and consequently a high LL. In addition, the relationship of $\mathrm{L}_{4-5} \mathrm{I}$ and $\mathrm{LL}$ could be determined by two different algorithms: 1) $L L=0.5919 * L_{4-5} l+29.461$ (26) or 2) $L L=0.5555{ }^{*} L_{4-5} I+10.38$ (13). From both algorithms, it can

Table VI: Alteration of Spinopelvic Parameter Between the PLF and TLIF Groups

\begin{tabular}{lccc}
\hline $\begin{array}{l}\text { Alteration of } \\
\text { spinopelvic } \\
\text { parameter }\end{array}$ & PLF & TLIF & p \\
\hline $\mathrm{L}_{4-5} \mathrm{I}(95 \% \mathrm{Cl})$ & $-1(-17.9)$ & $-0.5(-12.9)$ & 0.458 \\
\hline $\mathrm{L}_{4-5} \mathrm{~S}(95 \% \mathrm{Cl})$ & $2(-13.18)$ & $3.5(-10.19)$ & 0.212 \\
\hline $\mathrm{L}_{4-5} \mathrm{~T}(95 \% \mathrm{Cl})$ & $-3(-21.7)$ & $-2.5(-24.13)$ & 0.755 \\
\hline $\mathrm{LL}(95 \% \mathrm{Cl})$ & $1(-22.26)$ & $6.5(-17.26)$ & 0.131 \\
\hline
\end{tabular}

Table VII: Correlation Between the Correction of Deformity and the Alteration of Spinopelvic Parameters in All Patients

\begin{tabular}{lcc}
\hline $\begin{array}{l}\text { Spinopelvic } \\
\text { Parameter }\end{array}$ & SD $(\mathbf{m m})$ & HOD $(\mathbf{m m})$ \\
\hline $\mathrm{L}_{4-5} \mathrm{I}$ & $0.158(p=0.115)$ & $-0.116(p=0.251)$ \\
\hline $\mathrm{L}_{4-5} \mathrm{~S}$ & $0.063(p=0.536)$ & $0.213(p=0.034)$ \\
\hline $\mathrm{L}_{4-5} \mathrm{~T}$ & $0.017(p=0.870)$ & $-0.180(p=0.073)$ \\
\hline $\mathrm{LL}$ & $-0.008(p=0.935)$ & $0.239(p=0.017)$ \\
\hline
\end{tabular}

be inferred that patients with a high $\mathrm{L}_{4-5} \mathrm{I}$ will show a high LL and correlate with our result. Consequently, with an increase in lordosis, there will be increased loading to the posterior complex of the lumbosacral spine, which can be a major cause of spondylolysis $(5,24,28,29,39)$. In addition, this may induce the development of spondylolisthesis because of a high $\mathrm{L}_{4-5} \mathrm{~S}$ $(5,7,8)$. Development of spondylolisthesis positions the center of gravity of the pelvis towards the anterior position $(16,18,19)$. Nevertheless, increased $L_{4-5} T$ but decreased $L_{4-5} S$ is found to compensate and prevent the center of gravity displacement (19). Interestingly, $L_{4-5} I$ was normal in patients with disk herniation $\left(\mathrm{L}_{4-5} \mathrm{I}=49.8^{\circ}\right)$ and degenerative disk disease $\left(\mathrm{L}_{4-5} \mathrm{I}\right.$ $\left.=51.6^{\circ}\right)$, but it was much higher $\left(\mathrm{L}_{4-5} \mathrm{I}=60.0^{\circ}\right)$ in patients with DLS $(24,38)$, indicating a predisposition to DLS in patients with a higher $L_{4-5} I$ (4). In this study, the surgical correction was aimed to realign the lumbar spine by PLF or TLIF. As a result, these operations were able to maintain $\mathrm{L}_{4-5} \mathrm{I}$ at less than $60^{\circ}$, and therefore, were also capable to alleviate DLS (4). To understand $L_{4-5} T$ and $L L$ is also crucial because they play a prominent role in regulating spinal deformity $(3,9,12,17,21$, $22,36,39$ ). Additionally, these are the parameters of choice to determine DLS management preoperatively. Finally, the aim of this surgical correction was to correct spondylolisthesis; therefore, the reduction in the distance of slippage and restoration of HOD was necessary. The TLIF procedure has been widely accepted since 1998 and is able to improve HOD effectively $(27,30,37)$. In the present study, unlike SD, HOD demonstrated a significant correlation with some of the sagittal spinopelvic parameters. Because HOD was the primary goal of surgical correction, HOD also changed simultaneously when there was an alteration of SD. Additionally, nerve roots were also decompressed. Finally, the spinopelvic parameters can be ultimately affected when SD is changed. There are three limitations of this study. First, an only L4-5 DLS adult patient was evaluated instead of a number of patients with various degrees of DLS. This has a benefit of illustrating ideal fused spinopelvic morphology but clinical applicability was limited. Second, our result may be limited by an only posterior approach with two types of lumbar interbody fusion in adult patients without a significant statistical difference. Third, potential sagittal alignment between various slip degrees of spondylolisthesis should also be taken into consideration.

\section{The Lessons Learnt}

1. Global spinal alignment is classified into LL and thoracic kyphosis. LL is the sagittal geometric parameter to better understand the development of lumbosacral spondylolis-

Table VIII: Correlation Between the Correction of Deformity and the Alteration of L4/5 DLS in the PLF and TLIF Groups

\begin{tabular}{lcccc}
\hline & \multicolumn{2}{c}{ SD $(\mathbf{m m})$} & \multicolumn{2}{c}{ HOD $(\mathbf{m m})$} \\
\hline $\mathrm{L}_{4-5} \mathrm{I}$ & $\mathbf{P L F}$ & TLIF & PLF & TLIF \\
\hline $\mathrm{L}_{4-5} \mathrm{~S}$ & $0.331(\mathrm{p}=0.09)$ & $-0.072(\mathrm{p}=0.695)$ & $-0.133(\mathrm{p}=0.306)$ & $-0.072(\mathrm{p}=0.696)$ \\
\hline $\mathrm{L}_{4-5} \mathrm{~T}$ & $-0.003(\mathrm{p}=0.981)$ & $0.195(\mathrm{p}=0.286)$ & $0.285(\mathrm{p}=0.026)$ & $0.021(\mathrm{p}=0.909)$ \\
\hline $\mathrm{LL}$ & $0.231(\mathrm{p}=0.074)$ & $-0.222(\mathrm{p}=0.222)$ & $-0.362(\mathrm{p}=0.004)$ & $0.092(\mathrm{p}=0.615)$ \\
\hline
\end{tabular}


thesis. The present study revealed that increasing the LL degree indicates improvement of the postoperative result which has met the objective.

2. The LL value normally ranges from $40^{\circ}$ to $60^{\circ}$ in adult population and is not dependent on age. A number of studies stated the importance of LL and spinopelvic parameters on proper standing alignment in children and adults.

3. $L_{4-5} \mathrm{l}$ is a constant parameter after adolescence and determines the favorable $\mathrm{LL}$. Increased $\mathrm{L}_{4-5} \mathrm{I}$ is a predisposing risk factor for spondylolisthesis progression. As a result, $\mathrm{L}_{4-5} \mathrm{I}$ values were very similar when compared pre and post operation. The value was significantly higher in DLS patients. In addition, increasing $\mathrm{L}_{4-5} \mathrm{~T}$ and decreasing $L_{4-5} S$ were due to compensation because of the progression of the displacement of the center of gravity of the pelvis anteriorly.

4. The relationship of $L L$ and $L_{4-5} l$ could be determined by using the following algorithms: $L L=0.5919{ }^{*} L_{4-5} I+29.461$ or $L L=0.5555{ }^{*} L_{4-5} I+10.38$. Therefore, preoperative and perioperative assessment should be done.

5. The objective restoration of $\mathrm{HOD}$ was significantly correlated with the changes in $\mathrm{LL}$ and $\mathrm{L}_{4-5} \mathrm{~S}$. There was no correlation with the SD. The changes in SD could indirectly affect pelvic parameters. Restoration of HOD seems to be the most important objective in DLS surgical correction.

\section{CONCLUSION}

In DLS patients, use of PLF and TLIF procedures to correct the spinal alignment resulted in discernible changes in spinopelvic parameters including $\mathrm{L}_{4-5} \mathrm{~S}$ and $\mathrm{L}_{4-5} \mathrm{~T}$. The TLIF procedure can correct HOD more than the PLF procedure. Moreover, a significant correlation was found between HOD and the changes in $\mathrm{LL}$ and $\mathrm{L}_{4-5} \mathrm{~S}$.

\section{REFERENCES}

1. Ahmad S, Hamad A, Bhalla A, Turner S, Balain B, Jaffray $D$ : The outcome of decompression alone for lumbar spinal stenosis with degenerative spondylolisthesis. Eur Spine J 26:414-419, 2017

2. Aoki Y, Nakajima A, Takahashi H, Sonobe M, Terajima F, Saito M, Takahashi K, Ohtori S, Watanabe A, Nakajima T, Takazawa M, Orita S, Eguchi Y, Nakagawa K: Influence of pelvic incidence-lumbar lordosis mismatch on surgical outcomes of short-segment transforaminal lumbar interbody fusion. BMC Musculoskelet Disord 16:213, 2015

3. Berjano P, Langella F, Ismael MF, Damilano M, Scopetta S, Lamartina C: Successful correction of sagittal imbalance can be calculated on the basis of pelvic incidence and age. Eur Spine J 23 Suppl 6:587-596, 2014

4. Buckland AJ, Vira S, Oren JH, Lafage R, Harris BY, Spiegel MA, Diebo BG, Liabaud B, Protopsaltis TS, Schwab FJ, Lafage V, Errico TJ, Bendo JA: When is compensation for lumbar spinal stenosis a clinical sagittal plane deformity? Spine J 16:971981,2016
5. Chang DG, Ha KY, Kim YH, Lee EW: Spinopelvic alignment by different surgical methods in the treatment of degenerative sagittal imbalance of the lumbar spine. Clin Spine Surg 30:E390-e397, 2017

6. Chen $Q$, Cao L, Bian C, Wang HR, Lin H, Li XL, Jiang $Y Q$, Dong J: Degenerative spondylolisthesis in the fifth lumbar vertebra and radiographic parameters: A correlation analysis. Clin Spine Surg 30:E1233-e1238, 2017

7. de Kunder SL, Rijkers K, van Kuijk SM, Evers SM, de Bie RA, van Santbrink $\mathrm{H}$ : A protocol of a randomized controlled multicenter trial for surgical treatment of lumbar spondylolisthesis: The Lumbar Interbody Fusion Trial (LIFT). BMC Musculoskelet Disord 17:417, 2016

8. Dohzono S, Toyoda H, Takahashi S, Matsumoto T, Suzuki A, Terai H, Nakamura H: Factors associated with improvement in sagittal spinal alignment after microendoscopic laminotomy in patients with lumbar spinal canal stenosis. J Neurosurg Spine 25:39-45, 2016

9. Feng Y, Chen L, Gu Y, Zhang ZM, Yang HL, Tang TS: Influence of the posterior lumbar interbody fusion on the sagittal spinopelvic parameters in isthmic L5-S1 spondylolisthesis. J Spinal Disord Tech 27:E20-25, 2014

10. Ferrero E, Ould-Slimane M, Gille O, Guigui P: Sagittal spinopelvic alignment in 654 degenerative spondylolisthesis. Eur Spine J 24:1219-1227, 2015

11. Försth $P$, Ólafsson $G$, Carlsson $T$, Frost A, Borgström F, Fritzell $P$, Öhagen $P$, Michaëlsson $K$, Sandén B: A randomized, controlled trial of fusion surgery for lumbar spinal stenosis. $N$ Engl J Med 374:1413-1423, 2016

12. Garbossa D, Pejrona M, Damilano M, Sansone V, Ducati A, Berjano P: Pelvic parameters and global spine balance for spine degenerative disease: The importance of containing for the well being of content. Eur Spine J 23 Suppl 6:616-627, 2014

13. Ghandhari $H$, Hesarikia $H$, Ameri E, Noori A: Assessment of normal sagittal alignment of the spine and pelvis in children and adolescents. Biomed Res Int 2013:842624, 2013

14. Ghogawala Z, Dziura J, Butler WE, Dai F, Terrin N, Magge SN, Coumans J-VCE, Harrington JF, Amin-Hanjani S, Schwartz JS, Sonntag VKH, Barker FGI, Benzel EC: Laminectomy plus Fusion versus Laminectomy Alone for Lumbar Spondylolisthesis. N Engl J Med 374:1424-1434, 2016

15. Guha D, Heary RF, Shamji MF: latrogenic spondylolisthesis following laminectomy for degenerative lumbar stenosis: Systematic review and current concepts. Neurosurg Focus 39:E9, 2015

16. Ikuta K MK, Tominaga F, Sakuragi T, Kai K, Kitamura T, et al: Clinical and radiological study focused on relief of low back pain following decompression surgery in selected patients of lumbar spinal stenosis associated with grade I degenerative spondylolisthesis. Spine (Phila Pa 1976) 41(24):E1434-E1443, 2016

17. Kim YB, Kim YJ, Ahn YJ, Kang GB, Yang JH, Lim H, Lee SW: A comparative analysis of sagittal spinopelvic alignment between young and old men without localized disc degeneration. Eur Spine J 23:1400-1406, 2014 
18. Kitchen WJ, Mohamed M, Bhojak M, Wilby M: Neurogenic claudication secondary to degenerative spondylolisthesis: Is fusion always necessary? Br J Neurosurg 30:662-665, 2016

19. Kong LD, Zhang YZ, Wang F, Kong FL, Ding WY, Shen Y: Radiographic restoration of sagittal spinopelvic alignment after posterior lumbar interbody fusion in degenerative spondylolisthesis. Clin Spine Surg 29:E87-92, 2016

20. Labelle H, Mac-Thiong JM, Roussouly P: Spino-pelvic sagittal balance of spondylolisthesis: A review and classification. Eur Spine J 20 Suppl 5:641-646, 2011

21. Lafage V, Bharucha NJ, Schwab F, Hart RA, Burton D, Boachie-Adjei O, Smith JS, Hostin R, Shaffrey C, Gupta M, Akbarnia BA, Bess S: Multicenter validation of a formula predicting postoperative spinopelvic alignment. J Neurosurg Spine 16:15-21, 2012

22. Lafage V, Schwab F, Patel A, Hawkinson N, Farcy JP: Pelvic tilt and truncal inclination: Two key radiographic parameters in the setting of adults with spinal deformity. Spine (Phila $\mathrm{Pa}$ 1976) 34:E599-606, 2009

23. Lazennec JY, Folinais D, Bendaya S, Rousseau MA, Pour AE: The global alignment in patients with lumbar spinal stenosis: Our experience using the EOS full-body images. Eur J Orthop Surg Traumatol 26:713-724, 2016

24. Lee JH, Na KH, Kim JH, Jeong HY, Chang DG: Is pelvic incidence a constant, as everyone knows? Changes of pelvic incidence in surgically corrected adult sagittal deformity. Eur Spine J 25:3707-3714, 2016

25. Liu H, Li S, Wang J, Wang T, Yang H, Li Z, Li X, Zheng Z: An analysis of spinopelvic sagittal alignment after lumbar lordosis reconstruction for degenerative spinal diseases: How much balance can be obtained? Spine (Phila Pa 1976) 39:B52-59, 2014

26. Mac-Thiong JM, Labelle $H$, Roussouly P: Pediatric sagittal alignment. Eur Spine J 20 Suppl 5:586-590, 2011

27. McAfee PC, DeVine JG, Chaput CD, Prybis BG, Fedder IL, Cunningham BW, Farrell DJ, Hess SJ, Vigna FE: The indications for interbody fusion cages in the treatment of spondylolisthesis: Analysis of 120 cases. Spine (Phila Pa 1976) 30:S60-65, 2005

28. Mehta VA, Amin A, Omeis I, Gokaslan ZL, Gottfried ON: Implications of spinopelvic alignment for the spine surgeon. Neurosurgery 70:707-721, 2012

29. Menezes-Reis R, Bonugli GP, Dalto VF, da Silva Herrero CF, Defino HL, Nogueira-Barbosa MH: Association between lumbar spine sagittal alignment and $14-15$ disc degeneration among asymptomatic young adults. Spine (Phila $\mathrm{Pa}$ 1976) 41:E1081-1087, 2016
30. Min SH, Yoo JS: The clinical and radiological outcomes of multilevel minimally invasive transforaminal lumbar interbody fusion. Eur Spine J 22:1164-1172, 2013

31. Mori G, Mikami Y, Arai Y, Ikeda T, Nagae M, Tonomura H, Takatori R, Sawada K, Fujiwara H, Kubo T: Outcomes in cases of lumbar degenerative spondylolisthesis more than 5 years after treatment with minimally invasive decompression: Examination of pre- and postoperative slippage, intervertebral disc changes, and clinical results. J Neurosurg Spine 24:367374, 2016

32. Obeid I, Boissiere L, Yilgor C, Larrieu D, Pellise F, Alanay A, Acaroglu E, Perez-Grueso FJ, Kleinstuck F, Vital JM, Bourghli A: Global tilt: A single parameter incorporating spinal and pelvic sagittal parameters and least affected by patient positioning. Eur Spine J 25:3644-3649, 2016

33. Park SJ, Lee CS, Chung SS, Kang KC, Shin SK: Postoperative changes in pelvic parameters and sagittal balance in adult isthmic spondylolisthesis. Neurosurgery 68:355-363; discussion 362-363, 2011

34. Roussouly P, Pinheiro-Franco JL: Biomechanical analysis of the spino-pelvic organization and adaptation in pathology. Eur Spine J 20 Suppl 5:609-618, 2011

35. Sanchez-Mariscal F, Gomez-Rice A, Rodriguez-Lopez T, Zuniga L, Pizones J, Nunez-Garcia A, Izquierdo E: Preoperative and postoperative sagittal plane analysis in adult idiopathic scoliosis in patients older than 40 years of age. Spine J 17:5661, 2017

36. Schwab F, Lafage V, Patel A, Farcy JP: Sagittal plane considerations and the pelvis in the adult patient. Spine (Phila Pa 1976) 34:1828-1833, 2009

37. Sembrano JN, Yson SC, Horazdovsky RD, Santos ER, Polly DW Jr: Radiographic comparison of lateral lumbar interbody fusion versus traditional fusion approaches: Analysis of sagittal contour change. Int J Spine Surg 9:16, 2015

38. Shin EK, Kim CH, Chung CK, Choi Y, Yim D, Jung W, Park $\mathrm{SB}$, Moon JH, Heo W, Kim SM: Sagittal imbalance in patients with lumbar spinal stenosis and outcomes after simple decompression surgery. Spine J 17:175-182, 2017

39. Tebet MA: Current concepts on the sagittal balance and classification of spondylolysis and spondylolisthesis. Rev Bras Ortop 49:3-12, 2014

40. Wang H, Ma L, Yang DL, Ding WY, Shen Y, Zhang YZ: Radiological analysis of degenerative lumbar scoliosis in relation to pelvic incidence. Int J Clin Exp Med 8:2234522351, 2015

41. Zhu Z, Xu L, Zhu F, Jiang L, Wang Z, Liu Z, Qian BP, Qiu Y: Sagittal alignment of spine and pelvis in asymptomatic adults: Norms in Chinese populations. Spine (Phila Pa 1976) 39:E1-6, 2014 